\title{
Dependence of image quality of late gadolinium enhancement MRI of left atrium on number of patients imaged: results of multi-center trial DECAAF
}

Sathya Vijayakumar ${ }^{1,2 *}$, Eugene G Kholmovski ${ }^{3,2}$, Mark M Haslam², Nathan Burgon², Nassir F Marrouche ${ }^{2}$

From 17th Annual SCMR Scientific Sessions

New Orleans, LA, USA. 16-19 January 2014

\section{Background}

High-resolution late gadolinium enhancement (LGE) MRI is used to assess fibrosis of the left atrium (LA) and visualize post-ablation scar in patients with atrial fibrillation (AF). Only few centers with advanced expertise in cardiac MR (CMR) have shown successful and good quality LGE-MRI of the LA. In this work, we assess the dependence of image quality of LGE images on the number of patients imaged in the centers participating in the multi-center trial DECAAF (Delayed Enhancement - MRI determinant of successful Catheter Ablation of Atrial Fibrillation). Also, main causes of poor image quality were determined.

\section{Methods}

Fifteen centers with different degrees of CMR expertise and typical MRI hardware participated in DECAAF.

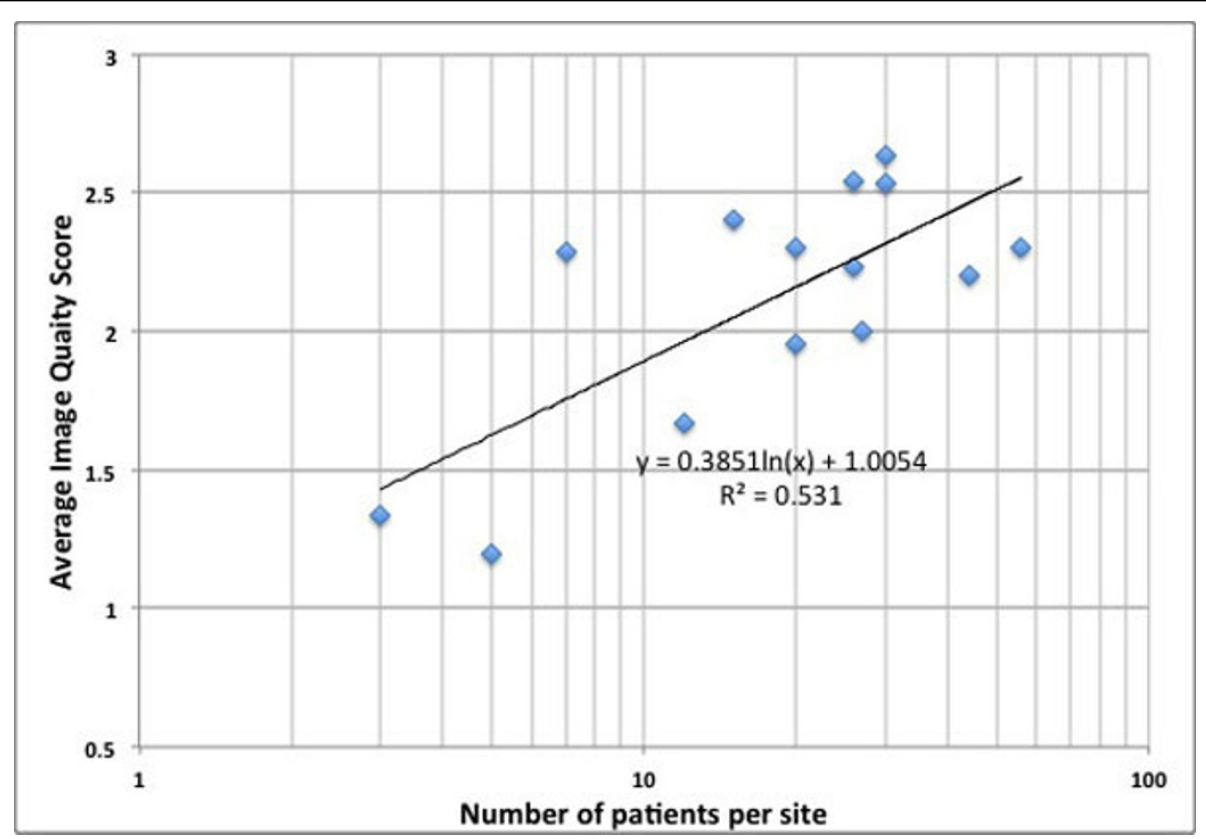

Figure 1 Dependence of image quality of LGE-MRI on number of patients imaged.

${ }^{1}$ Surgical Services Division, Intermountain Healthcare, Salt Lake City, Utah,

USA

Full list of author information is available at the end of the article 
Customized sequences for LGE of LA were installed on 17 Siemens scanners in participating centers. Nine centers used 1.5T scanners, five used 3T scanners and one used both 1.5 and $3 \mathrm{~T}$ scanners. Three hundred and twenty nine AF patients underwent LGE-MRI prior to ablation to estimate the extent of LA fibrosis. One center (8 patients) was excluded from analysis because of two-years of prior experience in LGE-MRI of LA. Two independent readers assessed the image quality as 1- poor, 2 - fair or 3 - good. Poor quality images (57 patients, $17.3 \%$ ) were analyzed to identify the causes for scan failure.

\section{Results}

Figure 1 shows the dependence of image quality on the number of patients imaged in each center. It was found that the average image quality score for centers that had imaged more than 20 patients $(2.35 \pm 0.23)$ was statistically significantly higher than the centers that had imaged less than or equal to 20 patients $(1.88 \pm 0.49)$ with $\mathrm{p}<$ 0.05 . Analysis of poor quality images indicated that in $63 \%$ of these scans MRI technologist error like wrong inversion recovery time, incorrect navigator prescription, wrong phase encode direction, incomplete coverage of the LA, was the main reason for poor image quality. In $30 \%$ cases, poor quality was patient related like significant arrhythmia, very irregular respiration, fast heart rate $(>120 \mathrm{bpm})$ and patient motion. Hardware limitations were responsible for $7 \%$ poor cases.

\section{Conclusions}

The analysis of data from multi-center study DECAAF clearly shows a learning curve associated with LGE MRI of LA - imaging more patients improves image quality. Better training of MRI technologists may also further improve image quality.

\section{Funding}

This study was supported by the CARMA Center at the University of Utah.

\section{Authors' details}

${ }^{1}$ Surgical Services Division, Intermountain Healthcare, Salt Lake City, Utah, USA. ' CARMA Center, University of Utah, Salt Lake City, Utah, USA. ${ }^{3}$ UCAIR, Dept. of Radiology, University of Utah, Salt Lake City, Utah, USA.

Published: 16 January 2014

doi:10.1186/1532-429X-16-S1-P146

Cite this article as: Vijayakumar et al: Dependence of image quality of late gadolinium enhancement MRI of left atrium on number of patients imaged: results of multi-center trial DECAAF. Journal of Cardiovascular Magnetic Resonance 2014 16(Suppl 1):P146.

\section{Submit your next manuscript to BioMed Central} and take full advantage of:

- Convenient online submission

- Thorough peer review

- No space constraints or color figure charges

- Immediate publication on acceptance

- Inclusion in PubMed, CAS, Scopus and Google Scholar

- Research which is freely available for redistribution

Submit your manuscript at www.biomedcentral.com/submit 